\title{
Esophageal perforation: diagnostic work-up and clinical decision-making in the first 24 hours
}

\author{
Jon Arne Søreide ${ }^{1,3^{*}}$ and Asgaut Viste 2,3
}

\begin{abstract}
Esophageal perforation is a rare and potentially life-threatening condition. Early clinical suspicion and imaging is important for case management to achieve a good outcome. However, recent studies continue to report high morbidity and mortality greater than $20 \%$ from esophageal perforation. At least half of the perforations are iatrogenic, mostly related to endoscopic instrumentation used in the upper gastrointestinal tract, while about a third are spontaneous perforations. Surgical treatment remains an important option for many patients, but a nonoperative approach, with or without use of an endoscopic stent or placement of internal or external drains, should be considered when the clinical situation allows for a less invasive approach. The rarity of this emergency makes it difficult for a physician to obtain extensive individual clinical experience; it is also challenging to obtain firm scientific evidence that informs patient management and clinical decision-making. Improved attention to nonspecific symptoms and signs and early diagnosis based on imaging may translate into better outcomes for this group of patients, many of whom are elderly with significant comorbidity.
\end{abstract}

Keywords: Esophagus, perforation, early diagnosis, surgery, non-surgical management, endoscopy

\section{Introduction}

Esophageal perforation is a well-characterized and potentially life-threatening clinical situation [1-3]. Several factors, including the difficulty of accessing the esophagus, the lack of a strong serosal layer, the unusual blood supply of the organ and the proximity of vital structures, all contribute to this condition's high morbidity and to a mortality rate of at least 20\% [4-6]. In addition, the diversity of clinical symptoms and signs combined with a lack of individual experience regarding this particular condition may impede rapid identification of this potentially hazardous situation. Accordingly, delayed diagnostic work-up may hinder timely and appropriate treatment with a negative effect on patient outcome [7].

The scientific evidence that guides management of esophageal perforation is based mainly on retrospective studies at single institutions as well as on a few nationwide studies [1,4-6,8-10]. Randomized studies are non-existent. Nevertheless, attention should be paid to early diagnosis

\footnotetext{
* Correspondence: jon.soreide@kir.uib.no

'Department of Gastroenterologic Surgery, Stavanger University Hospital, N4068 Stavanger, Norway

Full list of author information is available at the end of the article
}

and immediate treatment to save lives and to decrease morbidity and long-term sequelae.

In this review, we focus on the clinical aspects of esophageal perforation that are most helpful for early suspicion and that should prompt appropriate diagnostic tasks. We also highlight factors with particular clinical importance for informed decision-making during the first 24 hours of treatment in-hospital.

\section{Incidence and demographics}

The low incidence of esophageal perforation is supported by reports from institutional series that are often based on consecutive patients diagnosed over a period of decades [9,11-13]. However, referral bias and publication bias may obscure accurate incidence statistics. In a recent population-based study in Iceland, the age-standard incidence was 3.1/1 $000000 /$ year [6]. Nevertheless, the true incidence of esophageal perforation worldwide is not clear [14]. Most patients are in their sixties, and esophageal perforation is slightly more common in males [5].

\section{Causes}

Esophagus rupture is usually iatrogenic $[6,8,15]$, the result of endoscopic procedures [16] such as esophageal 
dilatation for strictures and for achalasia in particular [17]. It can also result from surgery on tissue that is in close proximity to the esophagus [18-20]. In about 15\% of the cases, there is spontaneous rupture with no known pre-existing pathology of the esophagus. This is mostly related to intense vomiting or severe retching, which probably causes an increase in intra-abdominal pressure. This clinico-pathologic entity, first described by Hermann Boerhave in 1724, was originally called Boerhave syndrome [21]. It is likely that very rare esophageal ruptures related to weight lifting, parturition, status epilepticus, defecation or to use of the Heimlich maneuver result from the same underlying mechanisms. Rare causes of perforation include external air-blast trauma [22] and blunt trauma [23].

Penetrating sharp injuries, i.e. external trauma, can damage the superficially located cervical esophagus as well as the thoracic portion of the esophagus. Although rare, gunshot wounds can cause tissue damage that can be easily missed during examination. Therefore, a high index of suspicion of esophageal perforation is warranted whenever there are penetrating injuries in this region [24].

In children, injuries to the esophagus are usually due to accidental ingestion of caustic liquids [25]. In contrast, the ingestion of caustic substances by adults is usually associated with suicidal intentions [26]. Cleaners, battery liquids and solutions used in industrial operations can generally be classified as acids or alkalis [27]. While acids, most of which have an unpleasant taste, produce coagulative tissue necrosis with a lower risk of penetration, alkalis tend to be more palatable and cause liquefactive necrosis that rapidly becomes transmural. The injuries and clinical consequences of ingestion of caustic substances depend on several factors, including the amount, viscosity and concentration of the agent, as well as on the duration of contact between the caustic agent and the esophageal mucosa.

\section{Symptoms and signs of esophageal perforation}

While chest pain is regarded as the cardinal symptom of esophageal perforation and is present in more than $70 \%$ of patients with a full thickness perforation of the intrathoracic esophagus, other symptoms and signs are variable and nonspecific in many patients. Notably, a missed diagnosis that was first made at autopsy has been reported in $17 \%$ of cases [6]. The pain associated with esophageal perforation is usually acute and sudden in onset, with radiation to the back or to the left shoulder. In about $25 \%$ of the patients, this pain is followed by vomiting and shortness of breath. The triad of vomiting, chest pain and subcutaneous emphysema is known as the Mackler triad [28].
There is neck pain when the cervical esophagus is perforated, although systemic symptoms are less common. Dysphonia, hoarseness, cervical dysphagia and subcutaneous emphysema are encountered in various combinations in this group of patients. There is sometimes acute abdominal or epigastric pain in patients with perforation of the gastroesophageal junction. Notably, perforations rarely manifest with hematemesis or other signs of gastrointestinal bleeding, including melena.

Most patients are in significant distress upon physical examination. Tachycardia is common, with fever $\left(>38.5^{\circ} \mathrm{C}\right)$ as a later sign. Attention should be paid as to whether there is crepitus in the neck region or at the chest wall, as this is characteristic of subcutaneous emphysema. A systemic inflammatory response usually develops rapidly after perforation, generally within 24-48 hours, and overwhelming bacterial mediastinitis may cause cardiopulmonary collapse and multiple organ failure (MOF) with a fatal outcome within a short period of time. Thus, diagnostic work-up should be performed as soon as esophageal perforation is considered a tentative diagnosis based on symptoms, signs, the patient's recent history (e.g. use of medical instruments or interventions in the esophagus, episodes of acute vomiting, ingestion of foreign bodies or agents) and careful clinical examination.

\section{Imaging and work-up}

Diagnosis of an esophageal perforation relies on radiographic evidence. Specifically, indirect signs of esophageal injury can be seen on a posteroanterior and lateral plain chest radiograph. Such signs include pleural effusion, pneumomediastinum, subcutaneous emphysema, hydrothorax, pneumothorax and collapse of the lung. However, a chest radiograph that uses a water-soluble contrast medium (if the patient can swallow) will reveal a contrast leak in most cases of esophageal perforation (Figure 1) [29]. Water-soluble contrast should be used instead of barium contrast to prevent barium-related inflammation of the mediastinum if there is perforation. If the initial contrastswallowing study is negative, imaging should be repeated after 4-6 hours if the clinical suspicion remains.

Computer tomography (CT) of the chest and upper abdomen with oral contrast can also show whether there is a leak [30](Figure 2). In addition, collection of air or fluid in the mediastinum, pleural effusions, pneumocardium and pneumoperitoneum are important diagnostic findings in these patients [31-33]. The site of perforation and the degree of containment may be easier to judge by $\mathrm{CT}$ than by plain chest X-ray. In critically ill patients and in those with external trauma or caustic injuries, a CT examination may provide additional information.

The role of upper endoscopy in the early diagnostic work-up of patients with suspected esophageal perforation 


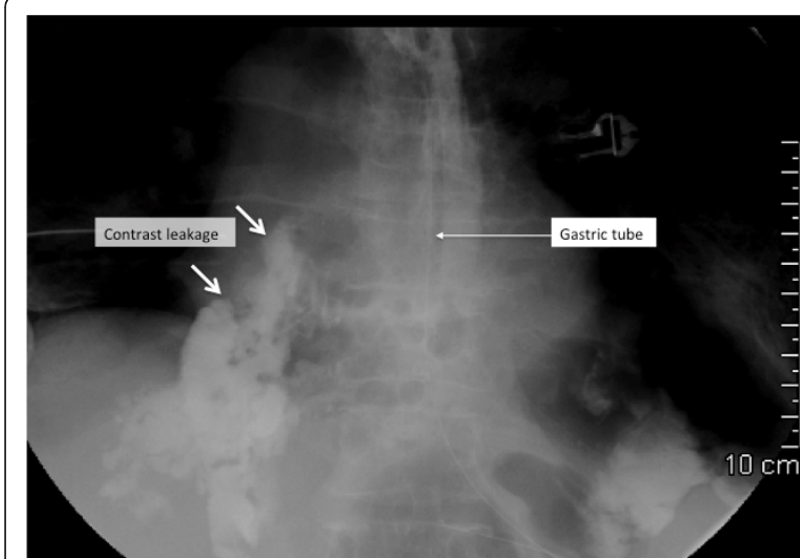

Figure 1 Plain chest radiography with a water soluble contrast swallow, showing contrast leakage in a patient with spontaneous rupture of the esophagus.

has been disputed [34]. In a patient with high suspicion of perforation with negative radiography, or when swallowing a contrast agent is impossible for technical reasons, flexible endoscopy should be considered. This widely available tool allows direct visualization of the entire esophagus and stomach and may also provide additional information

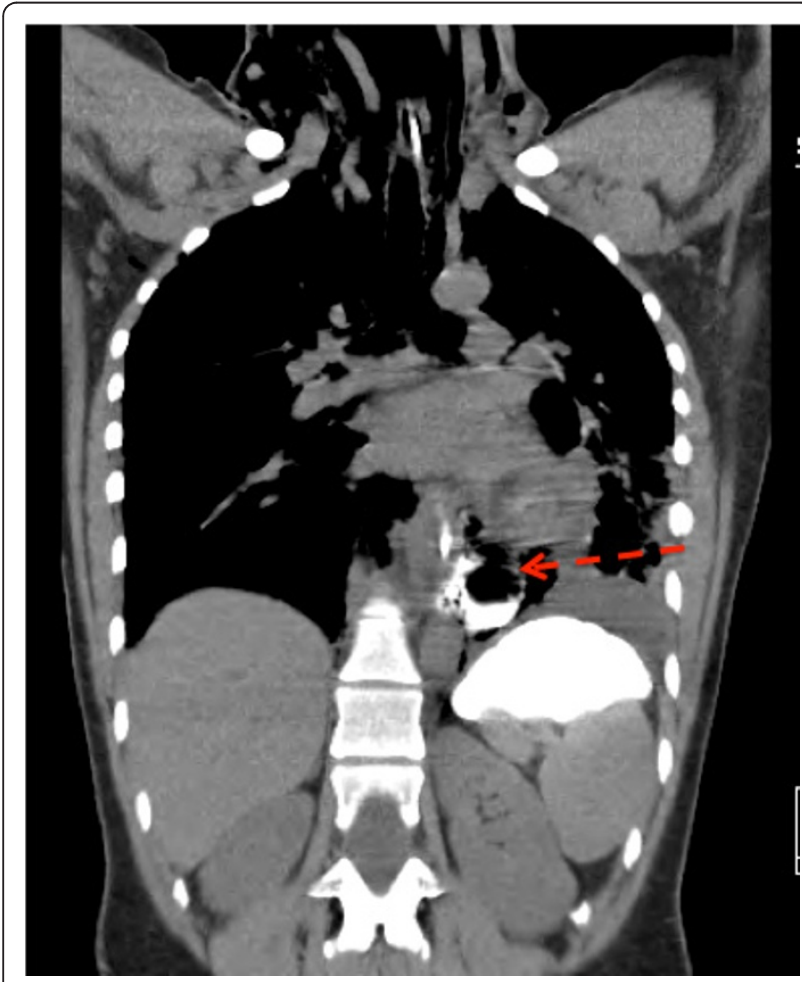

Figure 2 Computer tomography (CT) with an oral contrast swallow, showing distal contrast leakage and gas bubbles in the mediastinum only few hours after pneumatic dilatation for achalasia about the acute onset of symptoms in patients without previous instrumentation used in the esophagus (Figure 3).

\section{Early management and decision-making}

Patients with suspected esophageal perforation should be regarded as critically ill [21]. It is important to adopt an immediate and aggressive diagnostic approach to confirm the diagnosis and to identify related issues. Nil per mouth, intravenous fluids and appropriate pain treatment should be initiated. Broad-spectrum antibiotics should be given intravenously [1], and oxygen saturation should be monitored. Appropriate observation and management of these patients usually requires the resources of an intensive care unit along with careful and close surgical guidance and post-surgery surveillance.

While most surgical diseases of the esophagus are treated by gastroenterology surgeons or thoracic surgeons, depending on the country and institution where the patient is being treated, the attending surgeon should be familiar with basic treatment principles and with the interventions that should be considered depending on the individual presentation. It is key to determine the need for acute surgery or for alternative interventions in a timely manner.

Non-operative treatment is appropriate for many patients with iatrogenic perforation (e.g. perforation after dilatation for achalasia or benign strictures). In patients

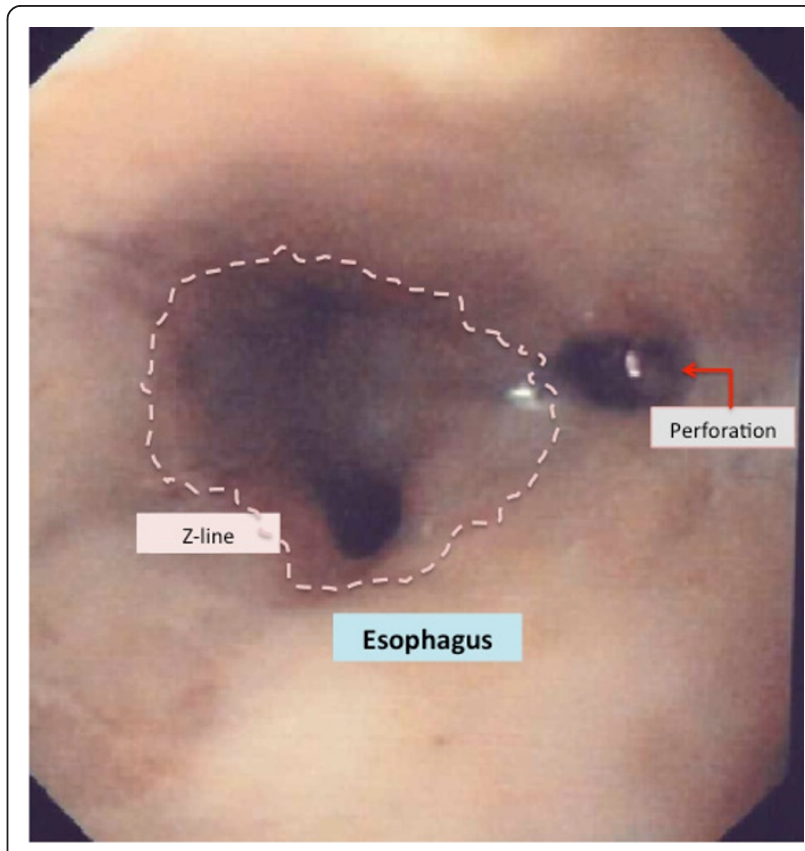

Figure 3 Endoscopic view of a distal spontaneous perforation 24 hours after onset of clinical symptoms, according to the patient. Endoscopic appearance, however, may suggest a time period exceeding at least 36-48 hours from onset of symptoms to endoscopic diagnosis. 
with limited injury to the esophageal wall and contained leakage without systemic symptoms of infection and compromised circulation, careful observation, nil per mouth, appropriate treatment with intravenous broadspectrum antibiotics and proton pump inhibitors (PPIs) and nutritional support may be sufficient for successful treatment [2]. Non-operative treatment should also be used when the perforation is related to an inoperable malignant stricture. Patient outcome depends mainly on the proper treatment of mediastinal and pleural contamination, and indications for percutaneous drainage or more extensive drainage by surgical intervention should be considered carefully if there is gross contamination.

Primary repair of esophageal perforation is possible, especially in patients admitted to the hospital within 24 hours of the event $[6,9,21,35-38]$. However, a recent study found that mortality risk was not related to wait time exceeding 24 hours [5]. When repair is attempted in iatrogenic cases with a stricture distal to the perforation, a myotomy might be indicated and the defect covered with a fundoplication. Repair over a T-tube is an alternative treatment that allows for a controlled esophago-cutaneous fistula to be established. This allows healing to take place without contamination [39]. The T-tube can be removed in most patients after 4-6 weeks, and the fistula will eventually close.

Exclusion and diversion of secretions of the esophagus are intended to expedite healing and, at the same time, minimize the risk of further contamination and infection [40]. This approach is rather complex and inconvenient for the patient, and the same results can usually be achieved by simpler procedures.

In the presence of a diseased esophagus with perforation, and in an acute situation, resection of the esophagus may be the most appropriate surgical procedure $[1,36,38]$. This is a major surgery, and mortality is high (15-40\%) and is mainly related to the cause of perforation (caustic perforation in particular), severity of sepsis and the patients' general condition [41]. Reconstruction may be delayed as necessary.

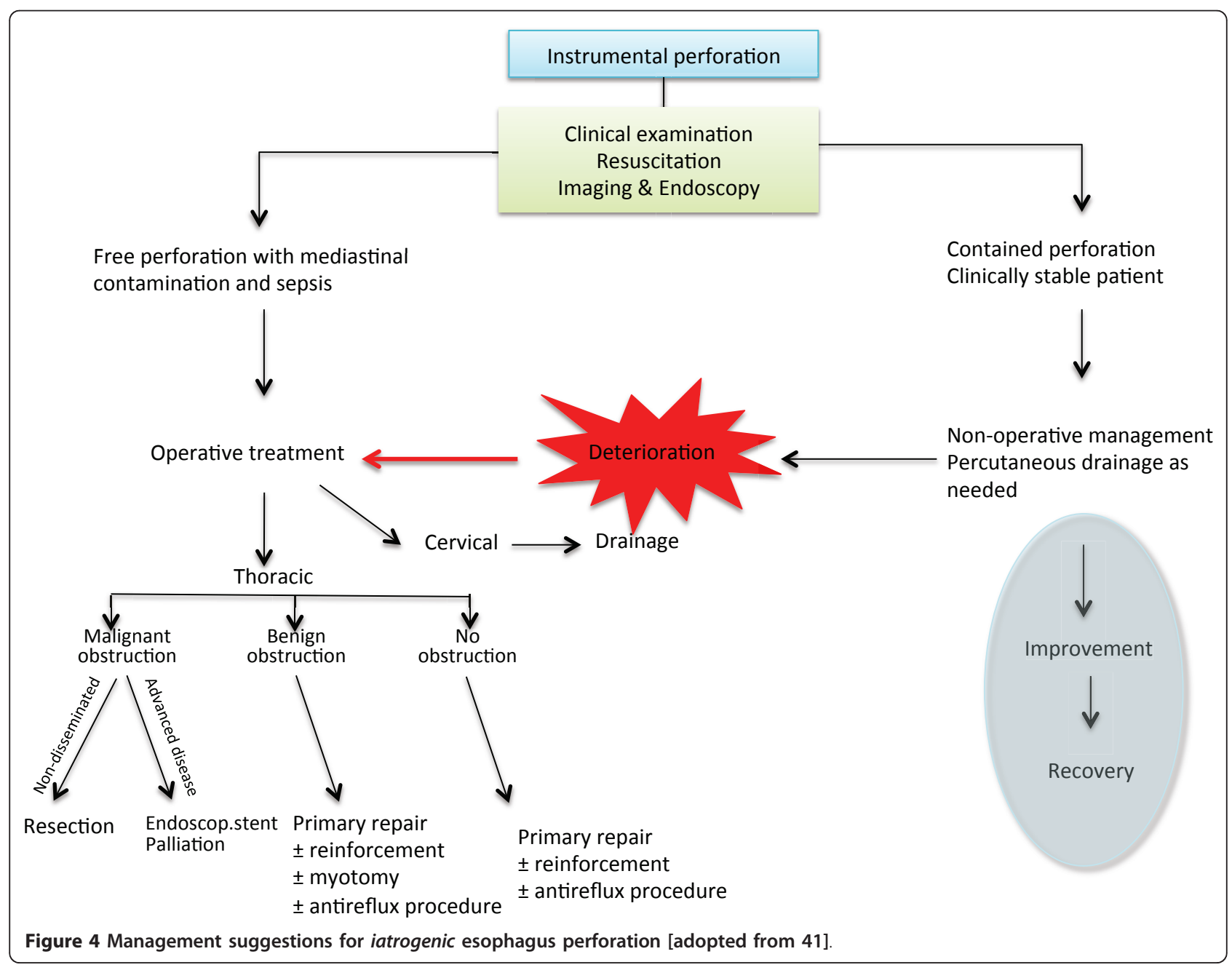


Recent reports emphasize a shift in treatment strategies over the last few decades, with non-operative approaches, such as percutaneous drainage of pleural effusions, collections or abscesses, becoming more common $[9,13,42]$. In addition, there is a growing use of temporary endoscopic esophageal stents to seal esophageal leakage and to recover gastrointestinal continuity [43-48]. Clinical experience with these treatments is based mostly on smaller series, but in selected patients this treatment seems promising. Use of endoscopic clips for perforation closure has been considered [49], and use of various stent types has been suggested [1,48,50-53]. Endoscopic vacuum sponge therapy has been introduced recently to aid successful drainage and healing of esophageal perforation or anastomotic insufficiency $[54,55]$. The roles of these new devices in the management of these patients are unclear. Nevertheless, while the rarity of esophageal perforation remains, the toolbox for treatment is growing. Thus, careful evaluation of each patient is mandatory to ensure proper management and care. Although sometimes too simplistic, algorithms can help guide physicians treating perforation of the esophagus. Algorithms for management of iatrogenic and spontaneous esophagus perforations, adopted from suggestions made by Shenfine \& Griffin [41], have been expanded and are shown in Figure 4 and 5.

\section{Discussion}

Timely diagnosis and appropriate treatment of esophageal perforation remains challenging, but both are important for managing patients $[4,5,9]$. Diagnosis can be difficult, due mainly to non-specific symptoms, and should include repeated and extended examination when there is clinical suspicion, even in patients who initially show negative imaging results. There are many treatment options, and a multidisciplinary approach is warranted. A main question would be, whether an immediate operative treatment is indicated or if a less-invasive non-operative approach should be employed. Measures such as antibiotics, PPIs, and so forth can be administered in the ICU as

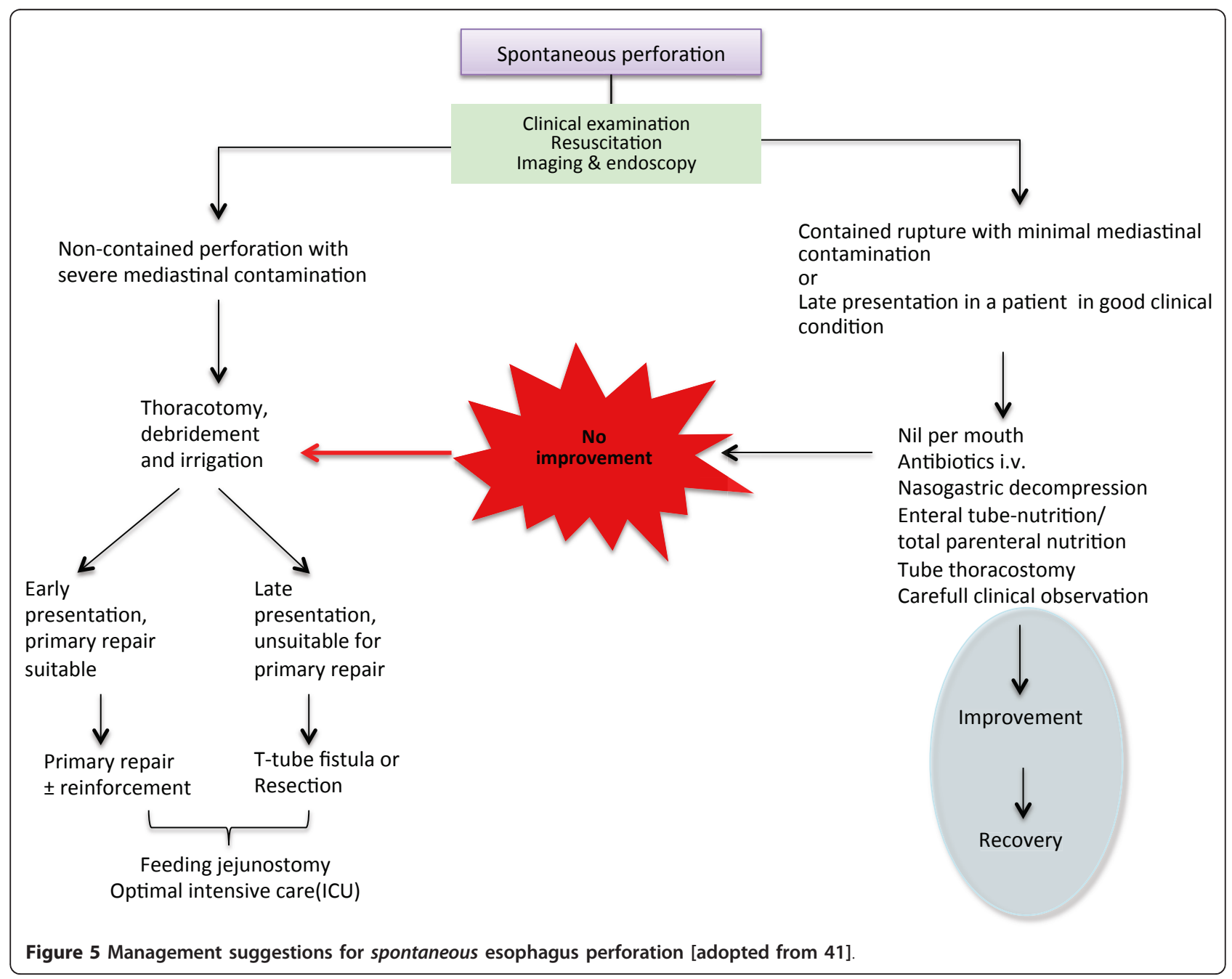


necessary. Percutaneous drainage or endoscopic therapeutic procedures should be considered according to the clinical situation of the patient (Figures 4 and 5).

The very low incidence of this potentially life-threatening condition makes it almost impossible for individual doctors to gain extensive clinical experience. However, referral of patients to a few major hospitals means that there are more of these patients treated at large teaching or university hospitals $[4,5,9,56]$. Nevertheless, every new case poses a clinical challenge for the physician in charge with regard to clinical evaluation and appropriate diagnostics. Consideration of each patients' overall condition in order to select the most appropriate treatment option adds to treatment complexity and highlights the need for a team approach to support surgical decision-making [9].

The rarity of esophageal perforation make it difficult or impossible to plan for prospective randomized studies with appropriate statistical power. Therefore, current recommendations for management of this group of patients are based mostly on recommendations from smaller institutional or from a few nation-wide patient series.

While there are many treatment options and approaches for perforation of the esophagus, early recognition of suspicious symptoms and signs by the emergency room physician is crucial for prompting the appropriate diagnostic steps. In turn, rapid diagnosis of this often life-threatening condition is critical for expediting the choice of an optimal treatment strategy, whether surgical or non-surgical.

\section{Author details}

'Department of Gastroenterologic Surgery, Stavanger University Hospital, N4068 Stavanger, Norway. ${ }^{2}$ Department of Gastroenterologic Surgery, Haukeland University Hospital, N-5021 Bergen, Norway. ${ }^{3}$ Department of Surgical Science, University of Bergen, N-5021 Bergen, Norway.

\section{Authors' contributions}

JAS conceived the study and provided an outline; JAS and AV searched and reviewed the literature, and made the interpretations of available data; JAS and AV drafted and critically revised the manuscript. Both authors read and approved the final manuscript.

\section{Competing interests}

The authors declare that they have no competing interests.

Received: 10 September 2011 Accepted: 30 October 2011

Published: 30 October 2011

\section{References}

1. Sepesi B, Raymond DP, Peters JH: Esophageal perforation: surgical, endoscopic and medical management strategies. Curr Opin Gastroenterol 2010, 26:379-383.

2. Abbas G, Schuchert MJ, Pettiford BL, Pennathur A, Landreneau J, Luketich JD, Landreneau RJ: Contemporaneous management of esophageal perforation. Surgery 2009, 146:749-755, discussion 755-746.

3. Skinner DB, Little AG, DeMeester TR: Management of esophageal perforation. Am J Surg 1980, 139:760-764.

4. Ryom P, Ravn JB, Penninga L, Schmidt S, Iversen MG, Skov-Olsen P, Kehlet $\mathrm{H}$ : Aetiology, treatment and mortality after oesophageal perforation in Denmark. Dan Med Bull 2011, 58:A4267.
5. Bhatia P, Fortin D, Inculet RI, Malthaner RA: Current concepts in the management of esophageal perforations: a twenty-seven year Canadian experience. Ann Thorac Surg 2011, 92:209-215.

6. Vidarsdottir H, Blondal S, Alfredsson H, Geirsson A, Gudbjartsson T: Oesophageal perforations in Iceland: a whole population study on incidence, aetiology and surgical outcome. Thorac Cardiovasc Surg 2010, 58:476-480.

7. Onat S, Ulku R, Cigdem KM, Avci A, Ozcelik C: Factors affecting the outcome of surgically treated non-iatrogenic traumatic cervical esophageal perforation: 28 years experience at a single center. J Cardiothorac Surg 2010, 5:46.

8. Vallbohmer D, Holscher AH, Holscher M, Bludau M, Gutschow C, Stippel D, Bollschweiler $E$, Schroder W: Options in the management of esophageal perforation: analysis over a 12-year period. Dis Esophagus 2010, 23:185-190.

9. Hermansson M, Johansson J, Gudbjartsson T, Hambreus G, Jonsson P, LilloGil R, Smedh U, Zilling T: Esophageal perforation in South of Sweden: results of surgical treatment in 125 consecutive patients. BMC Surg 2010, 10:31.

10. Udelnow A, Huber-Lang M, Juchems M, Trager K, Henne-Bruns D, Wurl P: How to treat esophageal perforations when determinants and predictors of mortality are considered. World J Surg 2009, 33:787-796.

11. Amudhan A, Rajendran S, Raj W, Rajarathinam G, Jyotibasu D, Ravichandran P, Jeswanth S, Balachandar TG, Kannan DG, Surendran R: Management of esophageal perforation: experience from a tertiary center in India. Dig Surg 2009, 26:322-328.

12. Chao YK, Liu YH, Ko PJ, Wu YC, Hsieh MJ, Liu HP, Lin PJ: Treatment of esophageal perforation in a referral center in taiwan. Surg Today 2005, 35:828-832.

13. Eroglu A, Turkyilmaz A, Aydin Y, Yekeler E, Karaoglanoglu N: Current management of esophageal perforation: 20 years experience. Dis Esophagus 2009, 22:374-380.

14. Byard RW: Esophageal causes of sudden and unexpected death. $J$ Forensic Sci 2006, 51:390-395.

15. Gander JW, Berdon WE, Cowles RA: latrogenic esophageal perforation in children. Pediatr Surg Int 2009, 25:395-401.

16. Merchea A, Cullinane DC, Sawyer MD, lqbal CW, Baron TH, Wigle D, Sarr MG, Zielinski MD: Esophagogastroduodenoscopy-associated gastrointestinal perforations: a single-center experience. Surgery 2010, 148:876-880, discussion 881-872.

17. Sanchez-Pernaute A, Aguirre EP, Talavera P, Valladares LD, de la Serna JP, Mantilla CS, de Leon AR, Torres A: Laparoscopic approach to esophageal perforation secondary to pneumatic dilation for achalasia. Surg Endosc 2009, 23:1106-1109.

18. Kau RL, Kim N, Hinni ML, Patel NP: Repair of esophageal perforation due to anterior cervical spine instrumentation. Laryngoscope 2010, 120:739-742.

19. Sreedharan L, Lakshmanan P, Shenfine J, Gibson MJ, Griffin SM: Thoracic vertebral osteomyelitis secondary to chronic esophageal perforation. Spine J 2009, 9:e1-5.

20. Ozer MT, Demirbas S, Harlak A, Ersoz N, Eryilmaz M, Cetiner S: A rare complication after thyroidectomy: perforation of the oesophagus: a case report. Acta Chir Belg 2009, 109:527-530.

21. Wolfson D, Barkin JS: Treatment of Boerhaave's Syndrome. Curr Treat Options Gastroenterol 2007, 10:71-77.

22. Roan JN, Wu MH: Esophageal perforation caused by external air-blast injury. J Cardiothorac Surg 2010, 5:130.

23. Strauss DC, Tandon R, Mason RC: Distal thoracic oesophageal perforation secondary to blunt trauma: case report. World J Emerg Surg 2007, 2:8.

24. Enguidanos L, Pfleiderer A, Smith W, Ramkumar S: Pneumomediastinum secondary to an apparently trivial stab wound to the neck: the value of the Hamman's sign and thorough radiological investigation. Emerg Med J 2005, 22:230-231.

25. Riffat $F$, Cheng A: Pediatric caustic ingestion: 50 consecutive cases and a review of the literature. Dis Esophagus 2009, 22:89-94.

26. Cheng HT, Cheng CL, Lin CH, Tang JH, Chu YY, Liu NJ, Chen PC: Caustic ingestion in adults: the role of endoscopic classification in predicting outcome. BMC Gastroenterol 2008, 8:31.

27. Rauber-Luthy $\mathrm{C}$, Kupferschmidt $\mathrm{H}$ : Household chemicals: management of intoxication and antidotes. EXS 2010, 100:339-363. 
28. Mackler SA: Spontaneous rupture of the esophagus; an experimental and clinical study. Surg Gynecol Obstet 1952, 95:345-356.

29. Vial CM, Whyte Rl: Boerhaave's syndrome: diagnosis and treatment. Surg Clin North Am 2005, 85:515-524, ix.

30. Sajith $A, O^{\prime}$ Donohue $B$, Roth RM, Khan RA: CT scan findings in oesophagogastric perforation after out of hospital cardiopulmonary resuscitation. Emerg Med J 2008, 25:115-116.

31. Exarhos DN, Malagari K, Tsatalou EG, Benakis SV, Peppas C, Kotanidou A, Chondros D, Roussos C: Acute mediastinitis: spectrum of computed tomography findings. Eur Radiol 2005, 15:1569-1574

32. Huber-Lang M, Henne-Bruns D, Schmitz B, Wuerl P: Esophageal perforation: principles of diagnosis and surgical management. Surg Today 2006, 36:332-340.

33. Young CA, Menias CO, Bhalla S, Prasad SR: CT features of esophageal emergencies. Radiographics 2008, 28:1541-1553.

34. Arantes V, Campolina C, Valerio SH, de Sa RN, Toledo C, Ferrari TA, Coelho LG: Flexible esophagoscopy as a diagnostic tool for traumatic esophageal injuries. J Trauma 2009, 66:1677-1682

35. Bresadola V, Terrosu G, Favero A, Cattin F, Cherchi V, Adani GL, Marcellino MG, Bresadola F, De Anna D: Treatment of perforation in the healthy esophagus: analysis of 12 cases. Langenbecks Arch Surg 2008, 393:135-140.

36. Richardson JD: Management of esophageal perforations: the value of aggressive surgical treatment. Am J Surg 2005, 190:161-165.

37. Muir AD, Graham A: Primary esophageal repair for Boerhaave's syndrome whatever the free interval between perforation and treatment. Eur $J$ Cardiothorac Surg 2005, 27:356, author reply 356.

38. Neel D, Davis EG, Farmer R, Richardson JD: Aggressive operative treatment for emetogenic rupture yields superior results. Am Surg 2010, 76:865-868.

39. Qadir I, Zafar H, Khan MZ, Sharif HM: T-tube management of late esophageal perforation. J Pak Med Assoc 2011, 61:418-420.

40. Kiernan PD, Rhee J, Collazo L, Hetrick V, Vaughan B, Graling P: Complete esophageal diversion: a simplified, easily reversible technique. J Am Coll Surg 2005, 200:812.

41. Schenfine J, Griffin SM: Oesophageal emergencies. In Oesophagogastric surgery - A companion to specialist surgical practice.. 3 edition. Edited by: Griffin SM, Raimes SA. Philadelphia: Elsevier Saunders; 2006:365-393.

42. Brinster CJ, Singhal S, Lee L, Marshall MB, Kaiser LR, Kucharczuk JC: Evolving options in the management of esophageal perforation. Ann Thorac Surg 2004, 77:1475-1483.

43. Zhou JH, Gong TQ, Jiang YG, Wang RW, Zhao YP, Tan QY, Ma Z, Lin YD, Deng B: Management of delayed intrathoracic esophageal perforation with modified intraluminal esophageal stent. Dis Esophagus 2009, 22:434-438.

44. Salminen P, Gullichsen R, Laine S: Use of self-expandable metal stents for the treatment of esophageal perforations and anastomotic leaks. Surg Endosc 2009, 23:1526-1530.

45. Leers JM, Vivaldi C, Schafer H, Bludau M, Brabender J, Lurje G, Herbold T, Holscher AH, Metzger R: Endoscopic therapy for esophageal perforation or anastomotic leak with a self-expandable metallic stent. Surg Endosc 2009, 23:2258-2262.

46. Freeman RK, Van Woerkom JM, Vyverberg A, Ascioti AJ: Esophageal stent placement for the treatment of spontaneous esophageal perforations. Ann Thorac Surg 2009, 88:194-198

47. Dai YY, Gretschel S, Dudeck O, Rau B, Schlag PM, Hunerbein M: Treatment of oesophageal anastomotic leaks by temporary stenting with selfexpanding plastic stents. Br J Surg 2009, 96:887-891.

48. Vahabzadeh B, Rastogi A, Bansal A, Sharma P: Use of a plastic endoprosthesis to successfully treat esophageal perforation following radiofrequency ablation of Barrett's esophagus. Endoscopy 2011, 43:67-69.

49. Qadeer MA, Dumot JA, Vargo JJ, Lopez AR, Rice TW: Endoscopic clips for closing esophageal perforations: case report and pooled analysis. Gastrointest Endosc 2007, 66:605-611.

50. Tuebergen D, Rijcken E, Mennigen R, Hopkins AM, Senninger N, Bruewer M: Treatment of thoracic esophageal anastomotic leaks and esophageal perforations with endoluminal stents: efficacy and current limitations. $\rfloor$ Gastrointest Surg 2008, 12:1168-1176.

51. Freeman RK, Van Woerkom JM, Ascioti AJ: Esophageal stent placement for the treatment of iatrogenic intrathoracic esophageal perforation. Ann Thorac Surg 2007, 83:2003-2007.
52. Bunch TJ, Nelson J, Foley T, Allison S, Crandall BG, Osborn JS, Weiss JP, Anderson $\mathrm{JL}$, Nielsen $\mathrm{P}$, Anderson $\mathrm{L}$, et al: Temporary esophageal stenting allows healing of esophageal perforations following atrial fibrillation ablation procedures. J Cardiovasc Electrophysiol 2006, 17:435-439.

53. Radecke K, Gerken G, Treichel U: Impact of a self-expanding, plastic esophageal stent on various esophageal stenoses, fistulas, and leakages: a single-center experience in 39 patients. Gastrointest Endosc 2005, 61:812-818.

54. Loske G, Schorsch T, Muller C: Endoscopic vacuum sponge therapy for esophageal defects. Surg Endosc 2010, 24:2531-2535.

55. Ahrens M, Schulte T, Egberts J, Schafmayer C, Hampe J, Fritscher-Ravens A Broering DC, Schniewind B: Drainage of esophageal leakage using endoscopic vacuum therapy: a prospective pilot study. Endoscopy 2010, 42:693-698.

56. Rueth N, Shaw D, Groth S, Stranberg S, D'Cunha J, Sembrano J, Maddaus M, Andrade R: Management of cervical esophageal injury after spinal surgery. Ann Thorac Surg 2010, 90:1128-1133.

doi:10.1186/1757-7241-19-66

Cite this article as: Søreide and Viste: Esophageal perforation: diagnostic work-up and clinical decision-making in the first 24 hours. Scandinavian Journal of Trauma, Resuscitation and Emergency Medicine 2011 19:66.

\section{Submit your next manuscript to BioMed Central and take full advantage of:}

- Convenient online submission

- Thorough peer review

- No space constraints or color figure charges

- Immediate publication on acceptance

- Inclusion in PubMed, CAS, Scopus and Google Scholar

- Research which is freely available for redistribution

Submit your manuscript at www.biomedcentral.com/submit
Ciomed Central 